\title{
ON THE ARRANGEMENT OF THE SEPTA IN EUPSAMMID CORALS
}

\author{
BY \\ C. J. VAN DER HORST, \\ Zoological Laboratory of the University of Amsterdam.
}

(With 14 Figures)

While studying the corals, collected by the Siboga-Expedition, I was impressed by the fact, that there is no agreement between different authors concerning the arrangement of the septa in the family Eupsammidae. According to the general law of voN KocH a new septum is formed invariably between two older ones, and that simultaneously around the entire circumference of the calicle according their classification. Therefore the number of septa of a given order equals the total number of septa of all preceding orders.

In the Eupsammidae we do not find this regularity. The septa belonging to the cycles of higher order are not all present. This irregularity has been a subject of study by different authors, the last of whom is vON MARENZELLER ').

As I have had very extensive material at hand, I have availed myself of the opportunity to restudy this question. I was enabled to study not only a great number of species, but also specimens of some species very different in age. To get a better survey I made diagrams of the septa in almost the same way as VON MARENZELLER did. In these diagrams I have indicated the situation of all septa of a calicle. My results differ from those of von MARENZELLER.

Starting with a specimen of Balanophyllia imperialis which has a calicle with a longitudinal diameter of $10,5 \mathrm{~mm}$. (fig. 1) we find a regular arrangement of septa that appears to be entirely in accord with the law of vON KocH. The septa of the first and second cycle alternate regularly with one another, between those the twelve septa of the third cycle are situated and again the twenty-four septa of the fourth cycle which are connected two and two with the intermediate septum of the third cycle, forming in that way a triangle in which the septum of the third cycle is perpendicular to the base.

Of these three connected septa it is not the middle one which is the best developed as might be expected, but that one which is situated nearest to a septum of the first cycle. This is the oldest of the three, the middlemost is the youngest one. This is also apparant from the way in which the septa are situated in regard to each other. Only the oldest extends to the columella, both the others are shorter and unite with the first. So we have here asymmetrical formation of new septa. But this asymmetry is not of long duration. The two youngest septa are nearly equally long and unite in the same place or nearly the same place with the older septum. The middlemost of the three becomes the plane of symmetry for the two others.

VON MARENZELLER arranges the septa in Balanophyllia in precisely this way. But he did not do so in Rhodopsammia, Thecopsammia, and Heteropsammia a procedure in my opinion quite wrong.

1) E. von MAREnZeller, Ueber den Septennachwuchs der Eupsamminen E. H. Expeditionen S. M. Schiff "Pola" in das Rote Meer. Zoologische Ergebnisse XXIV. Denkschr. kais. Ak. Wiss. Math.-naturw. K1. Bd. 80. Wien. 1907. 
By omitting the septa of the fifth and higher orders in the diagrams of vON MARENZELLER, we get the same scheme as in the above discussed Balanophyllia imperialis. The figures given by VON MARENZELLER, are derived from older and hence more intricate stages as will be discussed later on. For purpose of comparison I give a diagram of a younger Balanophyllia fistula (= Thecopsammia fistula in VON MARENZELLER's paper) (fig. 2) and from this it appears that there is no difference from Balanophyllia imperialis, only in Balanophyllia fistula the arrangement of the septa is still more apparant. And I obtained the same results in the examination of young specimens of Heteropsammia michelini.

During the further development we see that the middlemost of the three septa, the mutual arrangement of which has been already defined, grows more rapidly than the two others. It increases

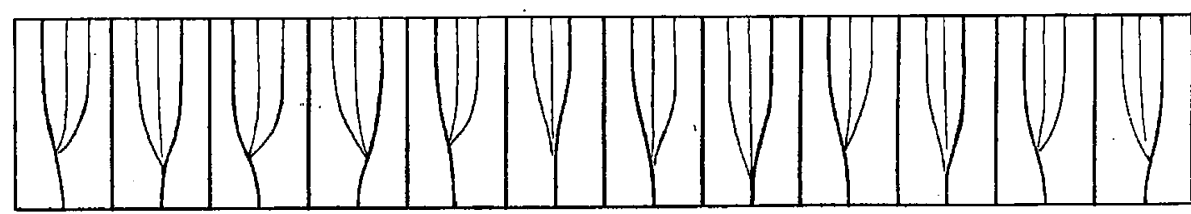

Fig. 1. Balanophyllia imperialis $(10,5 \mathrm{~m} . \mathrm{m}$.

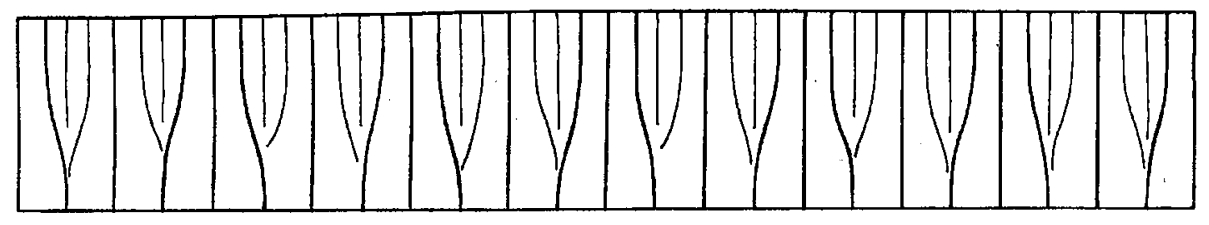

Fig. 2. Balanophyllia fistula $(7 \mathrm{m.m}$.

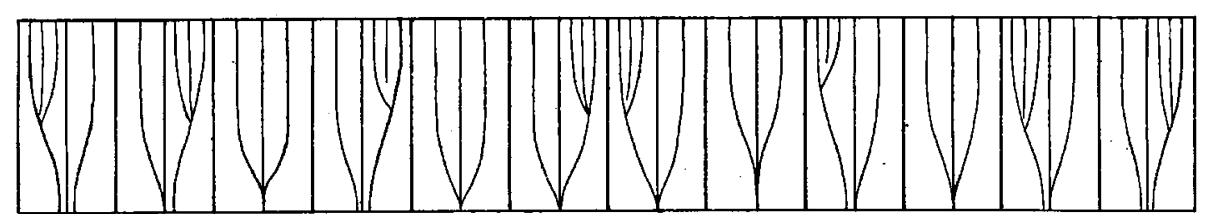

Fig. 3. Balanophyllia imperialis $(17 \mathrm{~m} . \mathrm{m}$.)

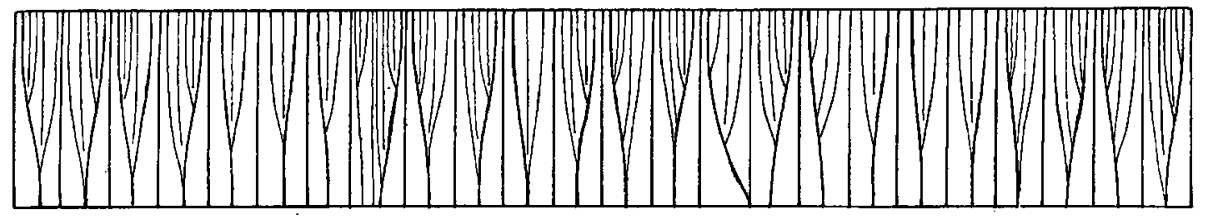

Fig. 4. Balanophyllia bairdiana (19 m.m.)

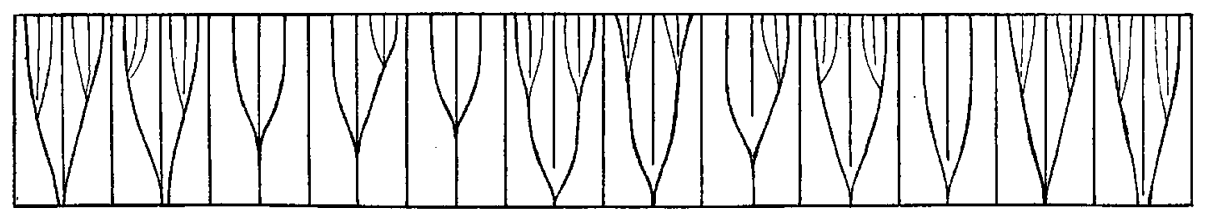

Fig. 5. Balanophyllia bairdiana $(8 \mathrm{~m} \cdot \mathrm{m})$ in thickness and breadth and then it seems to be the principal of the three. The place in which the three septa unite shifts continually nearer and nearer towards the columella, the younger septa becoming longer. In the oldest stage of Balanophyllia imperialis (greater diameter of the calicle 17 mm.) that I figure diagrammatically (fig. 3) the septa bend towards each other, but do not always fuse, some of these septa reach the columella independently of the others.

At the same time new cycles of septa are formed. The middlemost septum, the youngest but the best developed, has been the plane of symmetry for the two others. The new-formation of septa begins in the oldest of the three, thus asymmetrically. Often it remains asymmetrical. But in species with a great number of septa, for instance Balanophyllia bairdiana (fig. 4), Balanophyllia gigas, and Heteropsammia michelini the symmetry is soon restored. This is apparant in the diagram of Balanophyllia bairdiana (length of calicle $8 \mathrm{~mm}$.) (fig. 5) where symmetrical as well as asýmmetrical systems are to be seen. But in older specimens of the same species total symmetry exists again.

The new-formation of septa is always at that side of the two lateral septa which is turned towards the plane of symmetry, thus in the oldest, septum at the same side where new septa were formed the last time. But never will young septa unite with the middlemost septum, the plane of symmetry. This formation of new septa goes on in exactly the same way as before. Again two young septa are formed which are nearly equally long and unite with the older septum at the same place. In that way we get again numbers of three, the middlemost of the three is the youngest and becomes the 
plane of symmetry of both the others. The same may repeat itself again, as is to be seen in Balanophyllia bairdiana and Heteropsammia michelini.

Now we return to our starting point, Balanophyllia imperialis (length of calicle $10,5 \mathrm{~mm}$.). Comparison of this diagram with that of Heteropsammia michelini (fig. 6) shows a striking resemblance, except that all has been doubled in the latter. In the Balanophyllia we find again and again between two septa of the first cycle three septa, two younger septa having united with the two lateral ones of these. These lateral septa are symmetrically situated in regard to each other, the septum of the second cycle is the plane of symmetry between them. Is this middlemost
septum really the oldest of

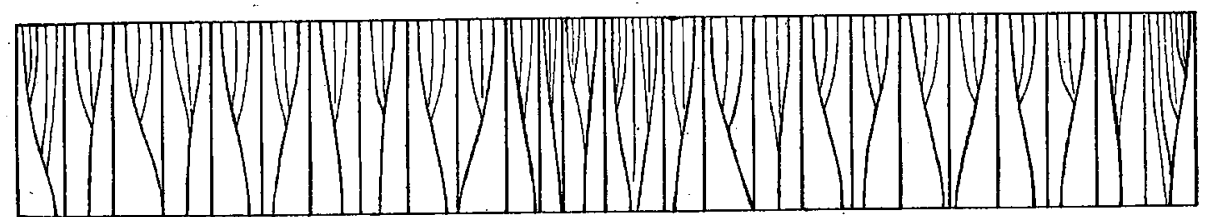
the three, is it therefore a septum of the second order, as it is generally considered to be or is this the same case as before, so that one of the two lateral septa is of the second order here? To verify this I have examined younger stages. In a Balanophyllia imperialis with the longer diameter of the calicle of $5,5 \mathrm{~mm}$. (fig. 7) it appears that the two lateral septa are inclined towards the septum of the second cycle, in some cases they are even united with it. In still younger stages this union takes place in each system. Moreover it is clear, that the formation of new septa has proceeded further at the side of one of the lateral septa than at that of the other, the new septa are longer at one side than at the other. The examination of still younger buds is dif-

Fig. 6. Heteropsammia michelini $(16$ m.m.)

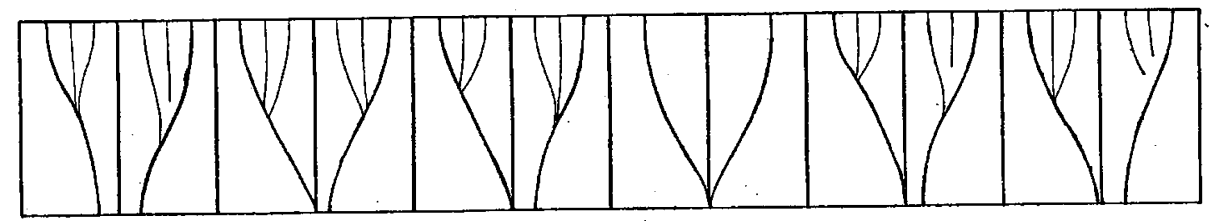

Fig. 7. Balanophyllia imperialis $(5,5$ m.m.)

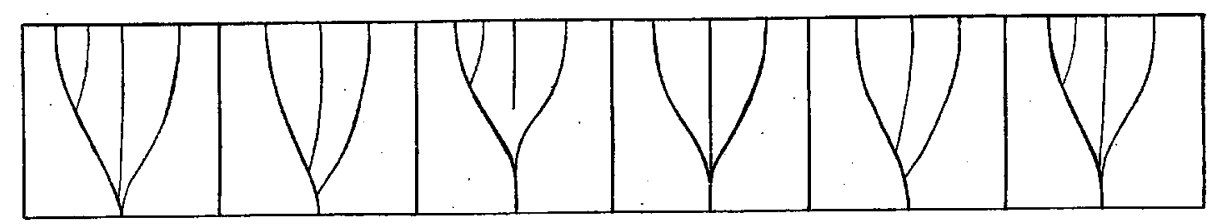

Fig. 8. Balanophyllia bairdiana (2 m.m.)

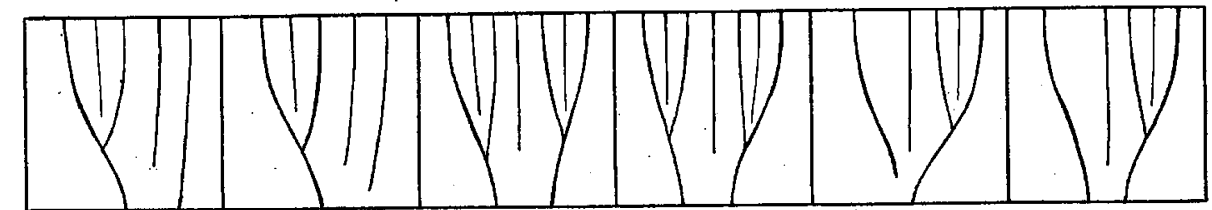

Fig. 9. Balanophyllia affinis (6,5 m.m.)

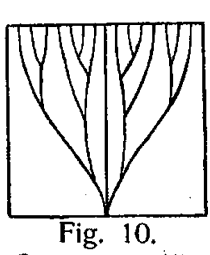

Stephanophyllia fungulus.

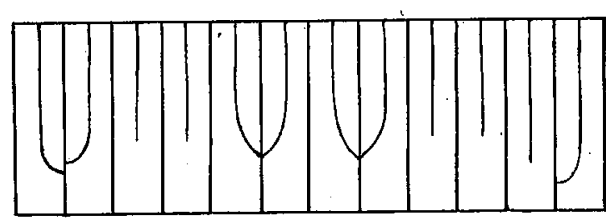

Fig. 11. Leptopsammia conica.

ficult, because the septa of these buds are hardly discernible from the trabecula of the parental corallite. I thought I could see the arrangement of the septa in a specimen of Balanophyllia bairdiana, two mm. in diameter, as is indicated in the diagram (fig. 8). A larger specimen of Balanophyllia affinis with a calicle of $6,5 \mathrm{~mm}$. width and in which the septa are clearly visible, does not leave the slightest doubt (fig. 9). In this specimen one of the lateral septa between two septa of the first order is always much more developed than the other and than the median one, this septum is the oldest of the three, without any doubt. The two others are formed in the same way as I have pointed out before in the case of the higher cycles.

According to LACAZE-DUTHIERS ${ }^{1}$ ) the twelve first septa are formed at the same time in the

1) H. DE LACAZE-DUthieRS, Faune du Golfe du Lion. Coralliaires. Zoanthaires sclerodermés. Deuxième mémoire. Ann. Zool. exp. et gen. Troisième série. Tome 5. 1897. 
young Eupsammidae. Six septa of these twelve grow more rapidly than the alternating other six and form the septa of the first cycle. Newly formed septa will never unite with them. But this is not the case with the six alternating septa, newly formed septa unite with them either at one or at the other side, but never at both. In each loculus absolute asymmetry prevails in that way, one half loculus becomes continually larger, the other continually smaller. New septa are formed only in the larger one. But taking into consideration the calicle as a whole the symmetry is very apparant, the long axis of the calicle is the axis of symmetry. This is clear in the diagrams of Balanophyllia imperialis $(5,5 \mathrm{~mm}$.) and Balanophyllia affinis.

I have examined representatives of all genera and species of the Eupsammidae that I had at hand and in each of them I found the same arrangement of the septa, with few exceptions. Of course there may be exceptions in one or two systems of a calicle, but those are mere abnormalities. The first real exception is found in the genus Stephanophyllia (fig. 10). I was able only to examine a few full-grown specimens of this genus. The difference between this genus and the normal type of the family seems to be that in Stephanophyllia only the septa of the second cycle become planes of symmetry, the other septa which should be planes of symmetry are not formed. In this case the difference is not so great.

But there is a great difference between the normal type and the genus Leptopsammia '). As is shown by LACAZE-DUTHIERS the younger septa in Leptopsammia are always formed contemporaneously on both sides of the older septum, according to the law of voN KoCH. These younger septa may be free at their inner extremity or they may bend towards the older septum and unite with it. This is illustrated in the diagram of Leptopsammia conica (fig. 11). LACAZE-DuTHIERS shows this difference between this genus and the normal type of the family clearly in the figures 3 and 12 placed near each other on Plate XI.

The terms cycle and order are generally used in the same sense by authors. VON MARENZELLER would wish to drop the term cycle and keep order only. I should like to keep both terms, but with different meanings. Order would then denote the genetical arrangement of the septa. In the same way as VON MARENZELLER I should make one exception here in relation to the twelve first septa. These are formed at the same time according to LACAZE-DuTHIERS but later on they act quite differently. Six grow more rapidly than the others, these six form the first cycle of septa. To these I would also give the name of septa of the first order, the alternating other six are the septa of the second order. The septa of the third and fourth order are formed asymmetrically and join those of the second order. My septa of the fourth order are the same as MARENZELLER's septa of the second order, they form the second cycle.

It may be better to keep the terme cycle in systematic descriptions to avoid disturbance of current nomenclature. As we have seen, the middlemost of each couple of three septa grows faster than the two others, it becomes the principal of the three. The oldest septum of the three bends at the place where the two others join it, in that way the middlemost seems to be the continuation of the inner part of the oldest septum. Therefore this inner part was looked upon by previous authors as belonging to a lower order

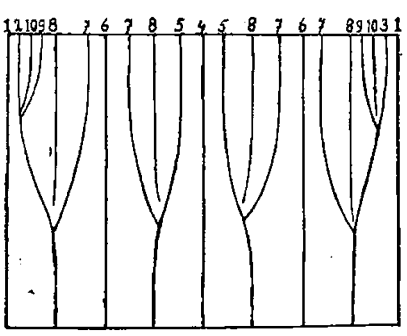

Fig. 12. Orders.

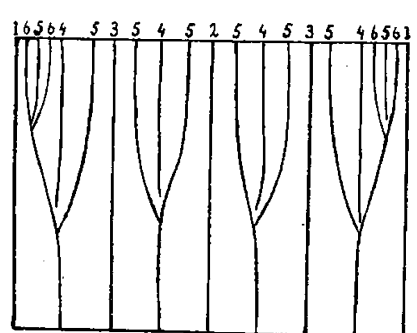

Fig. 13. Cycles. and cycle of septa than the two lateral ones.

The difference between order and cycle may appear from the two accompanying schemes (fig. 12 and 13).

Compared with other corals that may accord with the law of vON KOCH in the Eupsammidae the different orders of septa are always incomplete, there may be more septa of the same order in each system, but yet they are incomplete. The cycles on the contrary may be complete or they may not. This may be a character of the species or it depends on the age of the calicle.

1) According to MILNE-EDWARDS and HAIME Endopsammia wholly agrees with Leptopsammia with regard to the septa; it may be better to unite these two genera. Pourtalès gives as a definition of his genus Trochopsammia: "Balanophylliae with non-coalescent septa". I could not examine the genus, it may be that the following applies to this genus too. 
Dr. T. WaYland Vaughan kindly read the manuscript of this article and sent me some sketches on the septal sequence of Endopachys maclurii that he made in 1904. With the permission of Doctor VAUGHAN I figure here one of his sketches (fig. 14), illustrating the septal arrangement in the adult stage of this coral. The inner row of numbers refers to the cycles, the outer row to the orders. From comparison of this sketch with my figure 12 , which shows the orders, it may be clear that VAUGHAN does not make a difference, at least not in this sketch, between two septa formed at nearly the same time on one side of an older septum with which they are united. Because of that difference in interpretation I get a greater number of orders. By considering that the septa are formed at the same time or nearly so, it is clear that VAUGHAN is of the same opinion as I am relating to the septal sequence in the Eupsammidae. VaUGHAN's figure is of value because it also illustrates the relation between the exocoelic and entocoelic septa. VAUGHAN writes me that it is his opinion that the really important matter is the introduction of new septa in pairs and that perhaps it might be better to use ordinal numbers for both entocoelic and exocoelic septa,

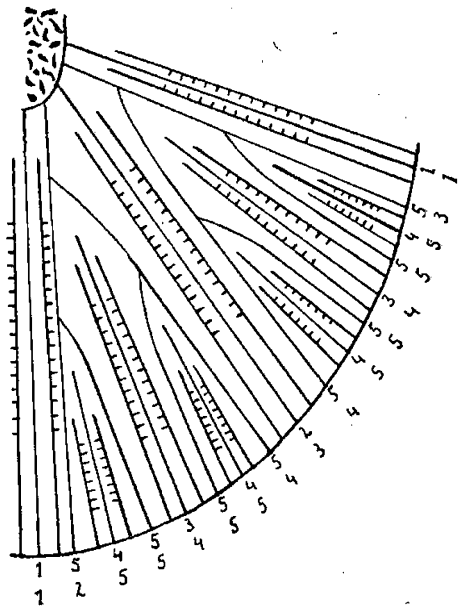

Fig. 14. instead of treating entocoelic and exocoelic septa belonging to the same pair either as of the same order or as belonging to successive orders. 